\title{
Numerical Method for the Analysis of Thermal Radiation on Heat Transfer in Nanofluid
}

\author{
J.I. Oahimire ${ }^{1 *}$, F.E Bazuaye ${ }^{2}$, Taylor S. Harry ${ }^{2}$ \\ ${ }^{1}$ Department of Mathematics, Michael Okpara University of Agriculture, Umudike, Nigeria \\ ${ }^{2}$ Department of Mathematics and Statistics, University of Port Harcourt, Port Harcourt, Nigeria
}

Received: July 02, 2016; Accepted: July 23, 2016; Published: July 30, 2016

*Corresponding author: Department of Mathematics, Michael Okpara University of Agriculture, Umudike, Nigeria, E-mail: imumolen@yahoo.co.uk

\begin{abstract}
This present study investigates the effects of thermal radiation on heat transfer in nanofluid. The governing equations are formulated base on already existing model and are transformed to ordinary differential equations using stream function and similarity variables. The resulting dimension less equations are then solved numerically by Runge-Kuta Fehlberg method with shooting techniques using Maple software. With the help of graphs and tables, influences of the governing parameters are discussed. The result shows that the radiation has significance influences on heat transfer.
\end{abstract}

Keywords: Nanofluid; Runge Kuta-Fehlberg method; Shooting technique; Heat transfer; Radiation

\section{Nomenclature}

$\mathrm{a}=$ Constant; $\mathrm{g}=$ Acceleration due to gravity; $\mathrm{k}=$ Thermal Conductivity; $\mathrm{P}_{\mathrm{r}}=$ Prandtl Number; $\mathrm{T}$ = Fluid Temperature; $\mathrm{T}_{\mathrm{w}}=$ Surface Temperature; $\mathrm{T}_{\infty}=$ Free Stream Temperature; $\mathrm{u}, \mathrm{v}=$ Velocity Components; $\mathrm{x}, \mathrm{y}=$ Cartesian Coordinates; $\mathrm{f}(\mathrm{x})$ = Dimensionless Stream Function; $G_{r}=$ Grashof Number; $q_{r}=$ Heat Flux Radiation; $\mathrm{B}_{\mathrm{o}}=$ Magnetic Field of Constant Strength; $\mathrm{R}=$ Radiation Parameter; $\mathrm{K}_{\mathrm{s}}=$ Rosseland Mean Absorption Coefficient; $\mathrm{K}=$ Thermal Conductivity Coefficient

\section{Greek Symbols}

$\beta=$ Thermal Expansion Coefficient $\mu=$ Dynamic Coefficient of Viscosity; $\theta(\eta)$ = Dimensionless Temperature; $\eta=$ Similarity Variable; $\rho=$ Fluid Density; $\psi=$ Stream Function; $\sigma^{\prime}=$ StefanBottzman Constant

\section{Introduction}

Nanofluid is formed when Nanoparticles such as Aluminium Oxide $\left(\mathrm{Al}_{2} \mathrm{O}_{3}\right)$, Copper ( $\left.\mathrm{Cu}\right)$, Copper Oxide (CuO), Gold $(\mathrm{Au})$, Silver (Ag), Silica particles, e.t.c are mixed with base fluids such as water, oil, acetone, ethylene, etc. The discovery of nanofluids in enhancing heat transfer in industrial processes has drawn the attention of both scholars and industrialists to make researches into this relatively new area.
Wang and Choi, [1] studied the thermal condutivity of nanoparticle fluid mixture containing $\mathrm{Al}_{2} \mathrm{O}_{3}$ and $\mathrm{CuO}$ nanoparticles and showed that the thermal conductivity of nanofluids increased with increasing volume fraction of the nanoparticles. Steve (2006) found out that a small size radiator filled with well prepared nanofluid containing monosized nanoparticles with $2 \mathrm{~nm}$ nominal diameter will be okay for heavy vehicle instead of a very big radiator and this will save cost and space. And he also discovered that fuel efficiency will be reduced by $5 \%$ in these Heavy Trucks when nanofluids are introduced into their cooling system. John and Baldev, [2] carried out experiment and they concluded that by controlling the linear aggregation length from nano- to macron scales, the thermal conductivity of the nanofluid can be tuned from a low to very high value and that under repeated magnetic cycling, the thermal conductivity is reversible.

Khan and Ipop, [3] studied the boundary-layer flow of a nanofluid past a stretching sheet and their result shows that the heat transfer at fixed values of the Lewis number $(L e)$, the Brownian motion parameter $(\mathrm{Nb})$ and the thermophoresis parameter $(N t)$ increases with the Prandtl number $(P r)$. This is because a higher $\operatorname{Pr}$ fluid has relatively lower thermal conductivity which reduces conduction and thereby increases the heat transfer rate at the surface of the sheet.

Godson, et al. [4] in separate papers agreed that Nanofluids are the most option to enhance heat transfer and showed that a very small amount of nanoparticles suspended stably in base fluids can provide impressive improvement in the thermal property of such fluids.

Zeinali and Salehi, [5] studied experimentally, the effect of magnetic field of various strengths on the thermal performance of Silver/water nanofluid and their results showed that the thermal efficiency in the presence of magnetic field increased.

Yohannes and Shankar, [6] examine the boundary layer flow of heat and mass transfer in MHD flow of nanofluids through porous media with viscous dissipation and chemical reaction. The governing boundary layer equations were formulated and 
reduced to a set of ordinary differential equations using similarity transformations and then solved numerically by an explicit finite differential scheme known as the Keller box method. Wan-Mohd, [7] applied Runge-kutta Fehlberg method and shooting technique for solving classical Blasius equation [7]. The well-known Blasius equation is governed by the third order nonlinear ordinary differential equation and then solved numerically using rungekutta Fehlberg method with shooting techniques. Hamad, [8] found analytical solution to the differential equations that model heat transfer in nanofliud. We extended the work of Hamad, [8] by incorporating radiation term to have differential equations that model the effect of thermal radiation on heat transfer of a nanofliud.

\section{Mathematical formulation}

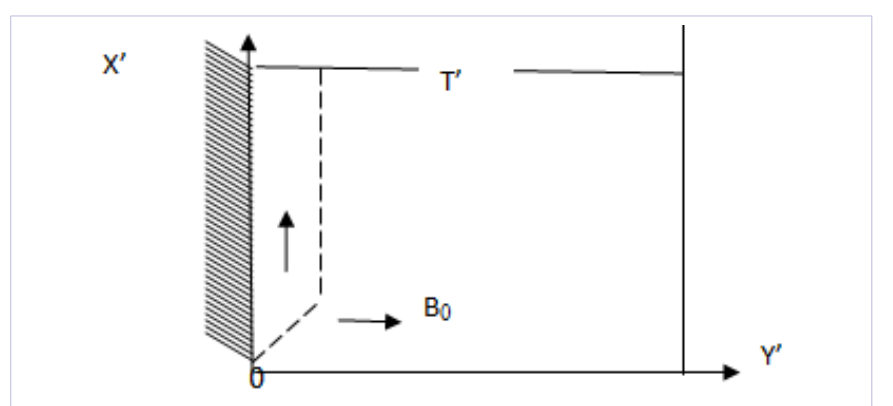

Figure 1

Consider the steady laminar two-dimensional flow of an incompressible viscous nanofluid past a linearly semi-infinite stretching sheet under the influence of a constant magnetic field of strength $\mathrm{B}_{0}$ which is applied normally to the sheet. $x^{\prime}$ and $y^{\prime}$ are the coordinates along and perpendicular to the sheet while $u^{\prime}$ and $v^{\prime}$ are the velocity components in the directions respectively as shown in the figure below:

A water based nanofluid containing different types of nanoparticles: $\mathrm{Al}_{2} \mathrm{O}_{3}, \mathrm{Cu}, \mathrm{TiO}_{2}$ and $\mathrm{Ag}$ is used with the assumption that both the fluid and the nanoparticles are in thermal equilibrium. Based on the already existing model of Hamad, [8], the governing boundary layer equations of continuity, momentum and heat equations formulated are:

$$
\begin{aligned}
& \frac{\partial u^{\prime}}{\partial x^{\prime}}+\frac{\partial v^{\prime}}{\partial y^{\prime}}=0 \\
& \rho_{n f}\left[u^{\prime} \frac{\partial u^{\prime}}{\partial x^{\prime}}+v^{\prime} \frac{\partial v^{\prime}}{\partial y^{\prime}}\right]=\mu_{n f} \frac{\partial^{2} u^{\prime}}{\partial y^{\prime 2}}-\sigma B_{0} u^{\prime}+g \beta_{t}\left(T^{\prime}-T_{\infty}^{\prime}\right) \\
& \left(\rho c_{p}\right)_{n f}\left[u^{\prime} ? \partial T^{\prime} / \partial x^{\prime}+v^{\prime} ? T^{\prime} /\left(? y^{\prime}\right)\right]=K_{n f}\left(\partial^{2} T^{\prime}\right) / \partial y^{\prime 2}-\left(\partial q_{r}\right) / \partial y^{\prime}
\end{aligned}
$$

The boundary conditions of the equations are

$$
\begin{aligned}
& u^{\prime}=u_{w}^{\prime}\left(x^{\prime}\right)=a x^{\prime}, v^{\prime}=0, T^{\prime}=T_{w}^{\prime} T_{w}^{\prime} \text { aty }=0 \\
& u^{\prime} \rightarrow 0, T^{\prime} \rightarrow T_{\infty}^{\prime}, y^{\prime} \rightarrow \infty
\end{aligned}
$$

Where $\mathrm{q}_{\mathrm{r}}$ is the radiative heat flux, $T^{\prime}$ is the temperature of the fluid, $x^{\prime}$ and $y^{\prime}$ are the co-ordinates along and perpendicular to the sheet while $u^{\prime}$ and $v^{\prime}$ are the velocity components in the $x^{\prime}$ and $y^{\prime}$ directions respectively and $a$ is a constant.

The effective density $\left(\rho_{n f}\right)$, effective dynamic viscosity $\left(\mu_{n f}\right)$, heat capacitance $\left(\rho C_{\mathrm{p}}\right)_{n f}$ and the effective thermal conductivity $\left(\mathrm{k}_{n f}\right)$ of the nanofluid, in that order, are given as

$$
\begin{aligned}
& \rho_{\text {th }}=(1-A) \rho_{f}+A \rho_{s} \\
& \mu_{f}=\frac{\mu_{f}}{(1-A)^{2.5}} \\
& \left(\rho C_{p}\right)_{f}=\left(1-A \gamma\left(\rho C_{p}\right)_{f}+A\left(\rho C_{p}\right)_{s}\right. \\
& k_{f}=k_{f}\left\{\frac{k_{s}+2 k_{f}-2 A\left(k_{f}-k_{s}\right)}{k_{s}+2 k_{f}+2 A\left(k_{f}-k_{s}\right)}\right\}
\end{aligned}
$$

Where $A$ is the solid volume fraction $(A \neq 1), \mu_{f}$ is the dynamic viscosity of the base fluid, while $\rho_{f}$ and $\rho_{s}$ are the densities of the pure fluid and the nanoparticle respectively. The constants $\mathrm{k}_{f}$ and $\mathrm{k}_{\mathrm{s}}$ are the thermal conductivities of the base fluid and the nanoparticle respectively.

Following Rosseland approximation Brewstar [9] the radiative heat flux $\mathrm{q}_{\mathrm{r}}$ is modeled as

$$
q_{r}=\frac{4 \sigma^{\prime}}{3 k^{\prime}} \frac{\partial T^{\prime 4}}{\partial y^{\prime}}
$$

Where $\sigma^{\prime}$ is the Stefan-Boltzman constant and $k^{\prime}$ is the mean absorption coefficient. Assuming that the difference in temperature within the flow is such that $T^{\prime 4}$ can be expressed as a linear combination of the temperature, we expand $T^{\prime 4}$ in Taylor's series about $T_{\infty}$ as follows:

$$
T^{\prime} 4=T_{\infty}^{\prime 4}+4 T_{\infty}^{\prime 3}\left(T^{\prime}-T_{\infty}^{\prime}\right)+6 T_{\infty}^{\prime 2}\left(T^{\prime}-T \infty^{\prime}\right)^{2}+\cdots \cdots
$$

and neglecting higher order terms beyond the first degree in $\left(T^{\prime}-T_{\infty}^{\prime}\right)$, we have

$$
T^{\prime 4} \approx-3 T_{\infty}^{; 4}+4 T_{\infty}^{\prime 3} T^{\prime}
$$

Differentiating equation (6) with respect to $y$ and using equation (8) to obtain

$$
\left.\left.\left.\partial q_{r}\right) / \partial y^{\prime}\right)=-16 T_{\infty}^{3} \sigma^{\prime}\right) / 3 k^{\prime}-\partial^{2} T^{\prime} / \partial y^{\prime 2}
$$

Then equation ( 3 ) becomes

$$
\left(\rho c_{p}\right)_{n f}\left[u^{\prime} \frac{\partial T^{\prime}}{\partial x^{\prime}}+v^{\prime} \frac{\partial T^{\prime}}{\partial y^{\prime}}\right]=K_{n f} \frac{\partial^{2} T^{\prime}}{\partial y^{\prime 2}}+\frac{16 T_{\infty}^{3} \sigma^{\prime}}{3 k^{\prime}} \frac{\partial^{2} T^{\prime}}{\partial y^{\prime 2}}
$$

By the introduction of the following variables

$$
\begin{aligned}
& u=u^{\prime} / \sqrt{a v_{f}} v=v^{\prime} / \sqrt{a v_{f}} \theta=\left(T^{\prime}-T^{\prime} \infty /\right. \\
& \left(T^{\prime} w-T^{\prime} \infty\right), x=x^{\prime} / \sqrt{\left(v_{f} / a\right)} \cdot y=y^{\prime} / \sqrt{v_{f} / a}
\end{aligned}
$$


Equation (11) transform equation (1), (2) and (10) to the followings

$$
\frac{\partial u}{\partial x}+\frac{\partial v}{\partial y}=0
$$

$u \frac{\partial u}{\partial x}+v \frac{\partial u}{\partial y}=\frac{1}{(1-A) \rho_{f}+\rho_{s}}\left(\frac{1}{(1-A)^{2.5}} \frac{\partial^{2} u}{\partial y^{2}}-M+G_{r} \theta\right)$

$u \frac{\partial \theta}{\partial x}+v \frac{\partial \theta}{\partial y}=\frac{1}{p_{r}} \frac{1}{\left(1-A \chi\left(\rho C_{p}\right)_{f}+A\left(\rho C_{p}\right)_{s}\right.}\left(\frac{k_{f}}{k_{f}}+R_{d}\right) \frac{\partial^{2} \theta}{\partial y^{2}}$

Where $M=\frac{\sigma \beta_{0}}{a}$ is the magnetic field parameter, $p_{r}=\frac{v_{f}}{K_{f}}$ is the Prandtl number, $R_{d}=\frac{16 \sigma^{\prime} T_{\infty}^{\prime 3}}{3 K^{*} K_{f}}$ is the radiation parameter, $G_{r}=\frac{g \beta_{t}\left(T_{w}^{\prime}-T_{\infty}^{;}\right) x}{a}$ Is the Grashof number

And the boundary conditions becomes

$$
\begin{aligned}
& u=x, v=0, \theta=1 \text { a } y=0 \\
& u \rightarrow 0, \theta \rightarrow 0 \text { o } y \rightarrow \infty
\end{aligned}
$$

By introducing the stream function $\psi$, which can be defined as

$$
\mathrm{u}=\frac{\partial \emptyset}{\partial \mathrm{y}}, \quad \mathrm{v}=-\frac{\partial \emptyset}{\partial \mathrm{x}} \text {. }
$$

and using the similarity transformations

$$
\eta=y, \psi=f(\eta) \theta=\theta(\eta)
$$

We have

$$
\begin{aligned}
& \left.f^{\prime \prime \prime}+(1-A)^{2.5}\left\{f f^{\prime \prime}-\left(f^{\prime}\right)^{2}\right\}\left[(1-A) \rho_{f}+\rho_{s}\right)-\left(M f^{\prime}+G_{r} \theta\right)\right]=0 \\
& \frac{1}{P_{r}} \frac{1}{\left(1-A \chi \rho C_{p}\right)_{f}+A\left(\rho C_{p}\right)_{s}}\left[\frac{k_{f}}{k_{f}}+R_{d}\right] \theta^{\prime \prime}(\eta)+f(\eta) \theta^{\prime}(\eta)=0
\end{aligned}
$$

And the boundary conditions now becomes

Table 1: Thermo physical properties of water and nanoparticles Hamad [8].

\begin{tabular}{|l|l|l|l|}
\hline Compound & $\boldsymbol{\rho}\left(\mathbf{k g} / \mathbf{m}^{3}\right)$ & $\boldsymbol{C}_{\boldsymbol{p}}(\mathbf{J} / \mathbf{k g K})$ & $\boldsymbol{k}(\mathbf{W} / \mathbf{m K}$ \\
\hline Pure water & 997.1 & 4179 & 0.613 \\
\hline Copper $(\mathrm{Cu})$ & 8933 & 385 & 401 \\
\hline Alumina $\left(\mathrm{Al}_{2} \mathrm{O}_{3}\right)$ & 3970 & 765 & 40 \\
\hline Silver $(\mathrm{Ag})$ & 10500 & 235 & 429 \\
\hline Titanium Oxide $\left(\mathrm{TiO}_{2}\right)$ & 4250 & 686.2 & 8.9538 \\
\hline An algan & & &
\end{tabular}

An algorithm was written and run with Maple codes to plot graphs and generate tables for analysis.

$$
\begin{aligned}
& f(0)=0, f^{\prime}(0)=1 \text { a } \quad \eta=0 \\
& f \rightarrow 0 \text { a } \eta \rightarrow \infty . \\
& \theta(0)=1 \text { and } \theta(\infty)=0,
\end{aligned}
$$

\section{Numerical Solution}

The thermo physical properties of pure water and those of the nanoparticles as given in table 1 by Hamad [8] will now be substituted in the transformed coupled ordinary differential equations. These equations will now be solved using RungeKutta-Fehlberg (RKF) method with shooting technique. The algorithm of Runge-Kutta-Fehlberg (RKF) method is order 5 and it gives a better approximation of the solution than the general Runge - Kutta method of order 4.

An algorithm was written and run with Maple codes to plot graphs and generate tables for analysis.

\section{Results}

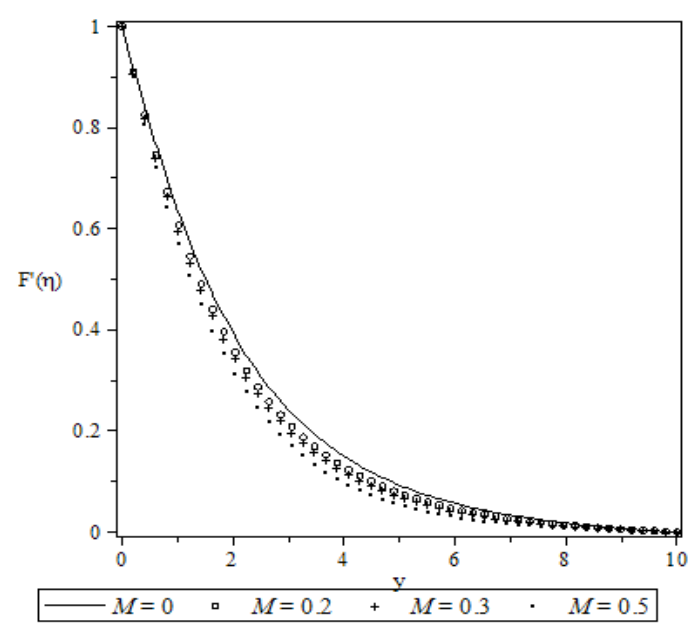

Figure 2: Effect of $\mathrm{M}$ on velocity distribution profiles.

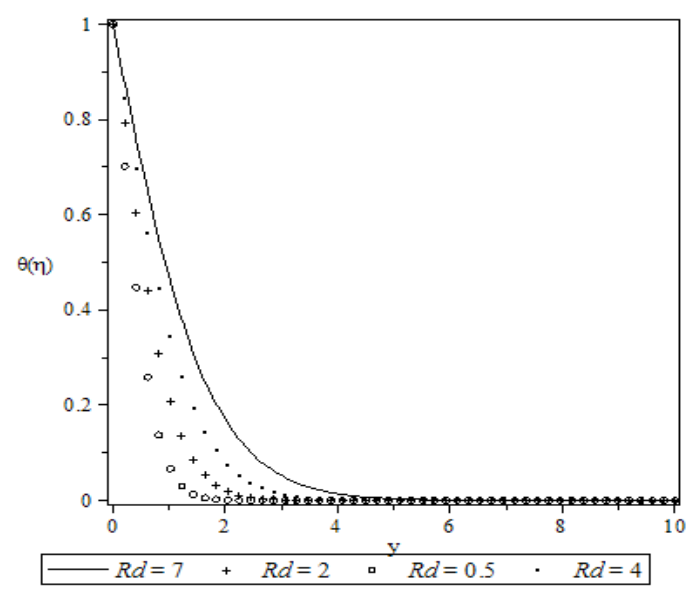

Figure 3: Effect of Rd on Temperature distribution profiles. 


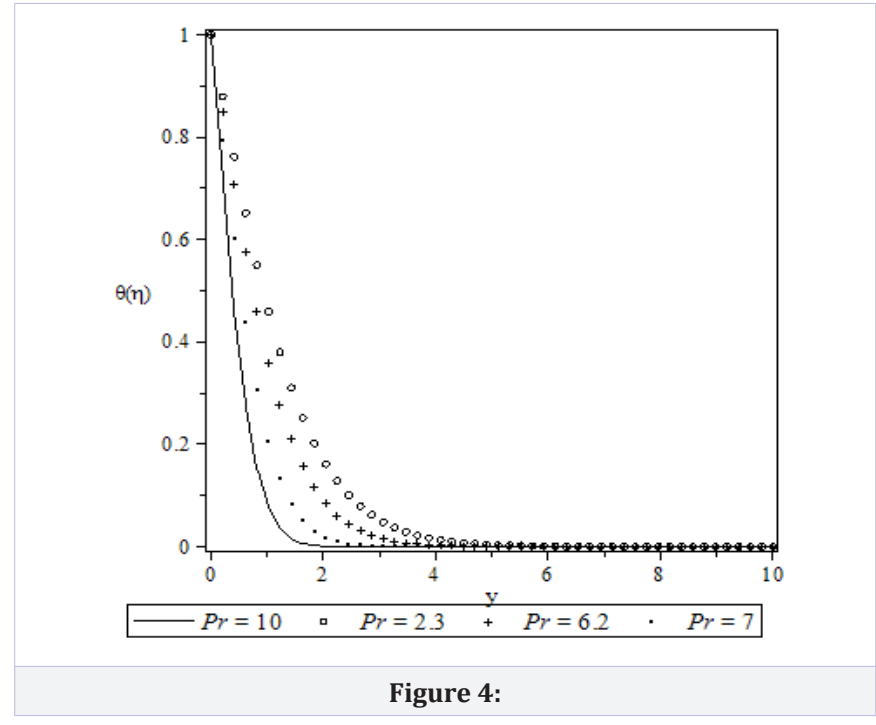

Table 2: Values of $-\theta^{\prime}(0)$ for various $\mathrm{Rd}$, A When $G r=0.1, M=0.5$ and $\operatorname{Pr}=6.2$.

\begin{tabular}{|l|l|l|l|l|l|}
\hline \multirow{2}{*}{ Rd } & \multirow{2}{*}{$\mathrm{A}$} & \multicolumn{3}{|l|}{$-\theta^{\prime}(0)$} & \multicolumn{2}{l}{} \\
\cline { 3 - 6 } & & $\mathrm{Cu}$ & $\mathrm{Ag}$ & $\mathrm{Al}_{2} \mathrm{O}_{3}$ & $\mathrm{TiO}_{2}$ \\
\hline $\mathbf{0 . 5}$ & 0.30 & 1.31430 & 1.23109 & 1.28489 & 1.28961 \\
\hline & 0.35 & 1.33022 & 1.23834 & 1.29732 & 1.30086 \\
\hline & 0.40 & 1.34938 & 1.24650 & 1.31206 & 1.31409 \\
\hline $\mathbf{2}$ & 0.45 & 1.37892 & 1.25349 & 1.33263 & 1.33158 \\
\hline & 0.30 & 0.85353 & 0.79483 & 0.83119 & 0.82915 \\
\hline & 0.35 & 0.86695 & 0.80360 & 0.84275 & 0.84011 \\
\hline $\mathbf{4}$ & 0.40 & 0.87137 & 0.80646 & 0.84654 & 0.84371 \\
\hline & 0.45 & 0.87576 & 0.80929 & 0.85030 & 0.84727 \\
\hline
\end{tabular}

Results are shown in figures 2- 3 and table 2

From derivation, the the Nuselt number can be written as follows;

$$
N u=-\theta^{\prime}(0)
$$

\section{Discussion of Results}

We have formulated the differential equations modeling the effect of radiation on heat transfer in nanofluid based on the already existing model. Numerical evaluation of the numerical solutions reported in the previous sections was performed and the results are presented in graphical and tabular forms. This was done to illustrate the influence of some parameter involved.

The effect of magnetic field parameter on velocity distribution profiles across the boundary layer is presented in Figure 1. It is obvious that the effect of increasing values of the magnetic field parameter $\mathrm{M}$ results in a decreasing velocity distribution. This is due to the fact that the introduction of transverse magnetic field normal to the flow direction has a tendency to create a drag force due to Lorentz force and hence results in retarding the velocity profiles Figure 2 shows the influence of the radiation parameter on the temperature distribution profiles. The temperature increases as the radiation increases. Figure 3 presents the temperature distribution profiles for different values of the Prandtl number (Pr). The results show that the effect of increasing values of the Prandtl number results in a decrease in the temperature.

In table 2 , as the radiation parameter increases, the nuselt number of the nanoparticles decreases, that is to say the effect of increasing the radiation parameters is to decrease the rate of heat transfer of the nanoparticles.Also, as the fraction volume parameter (A) increases, nuselt number increases.

\section{Conclusion}

Numerical solution was applied to the differential equation that model the effect of thermal radiation on heat transfer on nanofluid using runge-kutta Fehlberg method. It was found that the effect of high radiation is to decrease the rate of heat transfer.

\section{References}

1. Wang $\mathrm{X}, \mathrm{Xu} \mathrm{X}$, Choi SUS. Thermal conductivity of nanoparticle-fluid mixture. J. Therm. Physics Heat Transfer. 1999;13(4):474-80.

2. John P, Shima PD and Baldev R. Nanofluid with tunable thermal properties. Appl. Phys. Lett. 2008;92: 043108.

3. Khan WA and Pop I. Boundary- Layer flow of a nanofluid past a streching sheet. International Journal of Heat and Mass Transfer. 2010;53(11-12):2477-2483.

4. Godson L, Raja B, Mohan LD and Wongwises S. Enhancement of Heat Transfer Using nanofluids. Renewable and Sustainable energy Reviews. 2010; 14(2): 629 - 641.

5. Zeinali SH, Salehi H, Noie SH. The effect of Magnetic field and nanofluid on thermal performance of two-phase closed Thermosyphon (TPCT). Int. Journal of Physical Sciences. 2012;7(4):534 - 543. DOI: 10.5897/ IJPS11.1019.

6. Yohannes KY and Shankar B. Heat and mass transfer in MHD flow of nanofliuds through a porous media due to a stretching sheet with viscious disspation and chemical reaction effects. Caribbean journal of science and technology. 2013;1:001-017.

7. Wan-mohd KA, Biliana B, Nor-Ashirkin $A B$ and Rohana $A H$. Application of Runge-kutta-Fehlberg method and shooting technique for solving classical Blasius equation. World applied sciences journal. 2012;17:10-15

8. Hamad MAA. Analytical Solution of Natural convection flow of a Nanofluids over a linearly stretching sheet in the presence of magnetic field. International Communications in Heat and Mass Transfer. 2011;38(4):487-492.

9. Brewster MQ. Thermal radiation transfer properties. John Willey and sons. 1992; p. 6-9. 